\title{
THE EFFECT OF BILATERAL STELLECTOMY UPON THE CEREBRAL CIRCULATION OF MAN ${ }^{1}$
}

\author{
By HENRY A. SHENKIN, FERNANDO CABIESES, AND \\ GORDON VAN DEN NOORDT
}

\begin{abstract}
(From the Harrison Department of Surgical Research and the Neurosurgical Service of the Graduate Hospital of the University of Pennsylvania, Philadelphia)
\end{abstract}

(Submitted for publication July 13, 1950; accepted, October 23, 1950)

The role of the sympathetic nervous system in the intrinsic control of the cerebral circulation has always been controversial. Experiments heretofore have centered on the effects of stimulation of the cervical sympathetic nerves on changes in cerebral blood flow detected by instruments applied directly to the brain of animals. The results have generally agreed that cervical sympathetic stimulation causes only mild cerebral vasoconstriction. The marked effects of chemical agents $\left(\mathrm{CO}_{2}\right.$ in particular $)$ in affecting the cerebral circulation have led to the probably correct conclusion that the intrinsic control of the cerebral circulation in health is predominantly mediated via chemical agents in the blood and that neurogenic vasomotor control is at best only weakly effective (1). However, recent clinical reports (2-5), which we can confirm from personal experience, on the efficacy of temporary blockade of the stellate ganglia in ameliorating symptoms of cerebral embolism and thrombosis, presumably by relieving collateral vasospasm, have increased interest in the role of the sympathetic system in the intrinsic control of the disturbed cerebral circulation.

Harmel and associates (6) studied the effects of bilateral stellate ganglion block with procain on the cerebral circulation of 13 unanesthetized normotensive and hypertensive patients and failed to find any effect whatsoever. They utilized the recently introduced nitrous oxide technique for determination of the cerebral blood flow (7) in their studies. Scheinberg (8) has recently confirmed their work.

We have had the opportunity to study the cerebral circulation of seven patients before and after bilateral stellate ganglionectomy and our findings are the subject of this report.

1 This investigation was supported in part by a research grant from the National Institutes of Health, Public Health Service.

\section{METHODS}

Patients selected for study were necessarily suffering from abnormalities for which it was hoped bilateral stellate ganglionectomy would be of benefit. Four patients (L. S., M. M., J. W. and W. N.) had postencephalitic Parkinson's disease; one (B. D.) was clinically diagnosed as advanced cerebral arteriosclerosis; one (R. H.) had hypertension and advanced cerebral atrophy (air-encephalogram); and one (A. A.) suffered with an old hemiplegia as a complication of essential hypertension.

Cerebral blood flow (CBF) was determined by the nitrous oxide technique (7). Mean arterial blood pressure (MABP) was measured from the femoral artery by a damped mercury manometer attached directly to a needle in the artery. Blood oxygen and carbon dioxide analyses were carried out by the manometric technique of Van Slyke and Neill (9). Blood pH measurements were made anaerobically at $37^{\circ} \mathrm{C}$. using a glass electrode. Carbon dioxide tension in the blood $\left(\mathrm{pCO}_{2}\right)$ was calculated from the nomograms of Peters and Van Slyke (9). Cerebral vascular resistance (CVR) was calculated from the formula $C V R=\frac{\text { MABP }}{\text { CBF }}$ (7). Cerebral oxygen consumption (CMR) was determined by multiplying the CBF by the difference in oxygen content of the arterial and internal jugular blood.

Prior to operation a control cerebral blood flow measurement was made. At an interval of three to seven days following bilateral stellate ganglionectomy the studies were repeated. The patients were afebrile and received no premedication on either occasion. Earlier postoperative observations were precluded by the fact that general systemic changes (pulmonary effects and fever) would have obscured the results. This was unfortunate since it is well known that most vessels tend to regain a portion of their tone within several days after sympathectomy.

\section{RESULTS}

The most striking finding in the series as a whole was the significant fall of CVR following bilateral stellate ganglionectomy, from a mean value of 2.6 to 2.0 resistance units $(p<.02)$. There was not so clear an increase in the mean CBF from 45.6 to $55.6 \mathrm{cc} . / 100 \mathrm{~g} . / \mathrm{min}$. ( $\mathrm{p}>.05$ ) and in the CMR from 2.49 to $2.90 \mathrm{cc} . / 100 \mathrm{~g} . / \mathrm{min}$. (p < .9). Average values for the mean arterial blood pressure, 
pulse rate, cerebral respiratory quotient, jugular and arterial $\mathrm{pH}$ and $\mathrm{CO}_{2}$ tensions were relatively unaffected by the operative procedure.

Both internal jugular and arterial oxygen content were significantly $(\mathrm{p}<.02)$ decreased (by 1.3 Vol. \%) and the carbon dioxide content increased ( $3 \mathrm{Vol} . \%)$ following the bilateral removal of the stellate ganglia. These changes are probably due to a fall in the hematocrit postoperatively, and in one patient in whom the hematocrit was determined pre- and postoperatively such reduction did occur. The lowered hemoglobin content of the blood would result in reduction of the blood oxygen content. Blood with a lowered hematocrit would contain relatively greater amounts of plasma and since plasma does have a higher $\mathrm{CO}_{2}$ content than red cells one would expect the $\mathrm{CO}_{2}$ content of blood with a reduced hematocrit to be higher. However, since the $\mathrm{CO}_{2}$ tension of the blood was unaltered by operation the increased $\mathrm{CO}_{2}$ content of the blood could not be the critical factor in altering the cerebrovascular resistance postoperatively. Indeed, there is no correlation whatsoever between the changes in CVR with changes in any of the blood gas contents.

It is apparent that patients with initially slow CBF obtained the greatest reduction in CVR from the operation, and as a matter of fact an excellent correlation (Figure 1) exists between the preoperative $\mathrm{CBF}$ and amount of decrease in CVR $(r=.86)$.

Almost as good correlation (Figure 2) exists between the preoperative CVR and the fall in CVR $(r=.75)$.

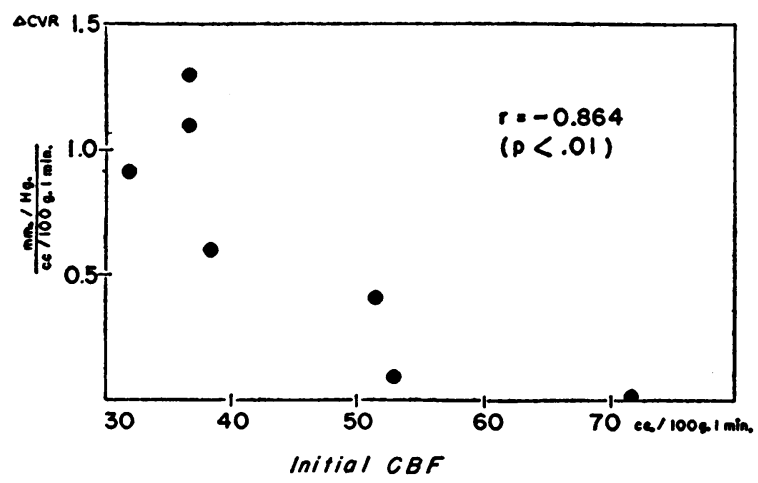

Fig. 1. Relationship of Fall in Cerebrovascular Resistance following Bilateral Stellectomy aNd Inttial Cerebral Blood Flow

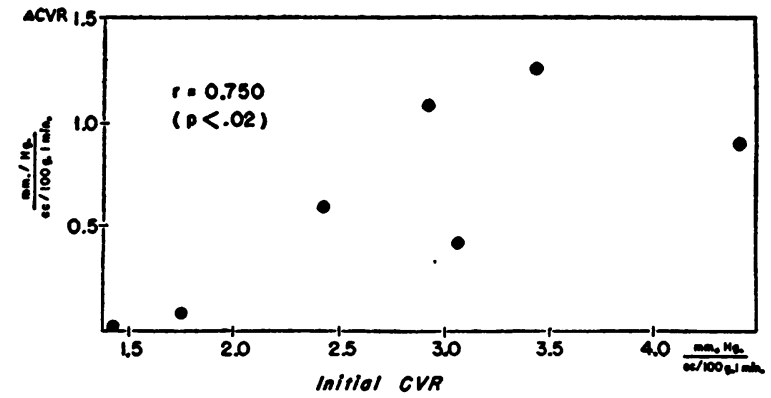

Fig. 2. Relationship of Fall - in Cerebrovascular Resistance following Bilateral Stellectomy aNd Inimial Cerebrovascular Resistance

\section{DISCUSSION}

Our data confirm previous findings, chiefly in animals, that under normal conditions the intrinsic tone of the cerebral vessels is not mediated via the autonomic nervous system fibers passing through the stellate ganglia. However, the clear effect of stellectomy in reducing the CVR in patients with abnormally slow $\mathrm{CBF}$ and increased CVR would indicate that, in pathologic states with increased CVR, at least a portion of this increased resistance can be due to spasm mediated over sympathetic reflexes.

The element of spasm maintained reflexly can evidently be considerably greater when induced by physiological means in the intact human than when produced in experimental animals by external, even though direct, stimulation of the sympathetic nerves.

The question whether the blood in the internal jugular bulb is significantly contaminated with drainage from the face and the scalp after stellate ganglionectomy and thereby influences our calculations of the cerebral blood flow and other cerebral circulatory functions is a pertinent one. Observations which demonstrated a very minor contamination of internal jugular bulb blood by extracerebral drainage were made on intact individuals (10). However, one would expect, if this error were introduced by the procedure of stellectomy, that the arteriovenous oxygen differences and respiratory quotients would be materially altered after operation. This in fact did not occur.

The discrepancy of our results with those reported by Harmel, Hafkenscheil, Austin, Crumpton and Kety (6) probably is due to the fact that 
TABLE I

Effect of bilateral stellate ganglionectomy on blood gas constituents

\begin{tabular}{|c|c|c|c|c|c|c|c|c|c|c|c|c|c|c|c|c|c|c|}
\hline \multirow{3}{*}{ Patient } & \multirow{3}{*}{ Age } & & \multicolumn{4}{|c|}{$\begin{array}{c}\text { Blood } \mathrm{CO}_{2} \text { content } \\
(\text { Vol. } \%)\end{array}$} & \multicolumn{4}{|c|}{$\begin{array}{c}\mathrm{Blood} \mathrm{CO}_{2} \text { tension } \\
(\mathrm{mm} . \mathrm{Hg})\end{array}$} & \multicolumn{4}{|c|}{$\begin{array}{c}\text { Blood } \mathrm{O}_{2} \text { content } \\
(V o l . \%)\end{array}$} & \multicolumn{4}{|c|}{ Blood pH } \\
\hline & & & \multicolumn{2}{|c|}{ Arterial } & \multicolumn{2}{|c|}{$\underset{\text { jugular }}{\text { Int. }}$} & \multicolumn{2}{|c|}{ Arterial } & \multicolumn{2}{|c|}{$\underset{\text { jugular }}{\text { Int. }}$} & \multicolumn{2}{|c|}{ Arterial } & \multicolumn{2}{|c|}{ jugular } & \multicolumn{2}{|c|}{ Arterial } & \multicolumn{2}{|c|}{$\underset{\text { jugular }}{\text { Int. }}$} \\
\hline & & & I & II & $\mathbf{I}$ & II & I & II & I & II & I & II & I & II & I & II & I & II \\
\hline L. S. & 38 & $\begin{array}{l}\text { Post-enceph. } \\
\text { Parkinsonism }\end{array}$ & $\overline{48.4}$ & 51.7 & 53.5 & 55.4 & 41 & 41 & 48 & 44 & $\overline{17.3}$ & 15.4 & $\overline{11.8}$ & 10.8 & $\overline{7.38}$ & 7.41 & 7.33 & $\overline{7.38}$ \\
\hline M. M. & 51 & $\begin{array}{l}\text { Post-enceph. } \\
\text { Parkinsonism }\end{array}$ & 49.9 & 57.2 & $\mid 55.0$ & 61.3 & 45 & 45 & 53 & 51 & $\mid 14.3$ & 12.4 & 9.0 & 8.2 & 7.34 & 7.40 & $\begin{array}{l}7.29 \\
\end{array}$ & 7.35 \\
\hline J. W. & 27 & Post-enceph. & 48.3 & 51.8 & 52.8 & 55.3 & 38 & 42 & 46 & 47 & 18.2 & 15.9 & 12.8 & 12.1 & 7.41 & 7.39 & 7.35 & 7.35 \\
\hline W. N. & 42 & $\begin{array}{l}\text { Post-enceph. } \\
\text { Parkinsonism }\end{array}$ & 50.3 & 53.2 & 54.5 & 58.7 & - & - & - & - & 17.7 & 15.9 & 13.0 & 10.3 & - & - & - & - \\
\hline A. A. & 43 & $\begin{array}{l}\text { Essential } \\
\text { hypertension }\end{array}$ & 51.0 & 53.8 & 55.9 & 59.6 & - & - & - & - & 14.0 & 13.1 & 8.8 & 7.0 & - & - & 一 & - \\
\hline R. H. & 51 & Cerebral & 47.6 & 47.3 & 52.5 & 54.5 & 38 & 38 & 44 & 46 & 20.4 & 19.9 & 14.2 & 11.9 & 7.44 & 7.42 & 7.38 & 7.37 \\
\hline B. D. & 59 & $\begin{array}{l}\text { Cerebral arte- } \\
\text { riosclerosis }\end{array}$ & 50.2 & 51.1 & 55.6 & 56.5 & 44 & 44 & 52 & 50 & 16.5 & 15.3 & 11.1 & 9.6 & 7.37 & 7.38 & 7.31 & 7.34 \\
\hline Mean & $\overline{44}$ & & $\overrightarrow{49.4}$ & $\overline{52.3 *}$ & $\overline{54.3}$ & \begin{tabular}{|l|}
$57.3^{*}$ \\
\end{tabular} & 41 & 42 & 49 & 48 & $\overline{16.9}$ & $\overline{15.4^{*}}$ & $\overline{11.2}$ & $10.0^{*}$ & 7.39 & 7.40 & 7.34 & $\overline{7.36}$ \\
\hline
\end{tabular}

I-Preoperative study

II-Post-bilateral stellate ganglionectomy study

* Denotes significant difference $(p<.02)$

the latter observers did not study patients with an initially reduced cerebrovascular resistance and cerebral blood flow. Scheinberg (8) did study such patients but performed only unilateral stellate blocks. Our results are based upon bilateral removal of the stellate ganglion.

We did not have the opportunity to study patients with acute cerebrovascular accidents. However, the marked reflex cerebral vasoconstriction demonstrated in some of our patients makes the existence of such a mechanism plausible in some cases of apoplexy and would explain the beneficial effects reported from stellate ganglia block in such instances. It also provides a rationale for cervical sympathectomy at the time of carotid ligation to overcome vasospasm that might result from reflex mechanisms brought into play, in some patients, by the ligation.

TABLE II

Effect of bilateral stellectomy on cerebral circulatory functions

\begin{tabular}{|c|c|c|c|c|c|c|c|c|c|c|c|c|}
\hline \multirow[t]{2}{*}{ Patient } & \multicolumn{2}{|c|}{$\begin{array}{l}\text { (CBF) } \\
\text { Cerebral } \\
\text { blood } \\
\text { flow }\end{array}$} & \multicolumn{2}{|c|}{$\begin{array}{c}\text { (CMRO }) \\
\text { Cerebral } \\
\mathrm{O}_{2} \text { con- } \\
\text { sumption } \\
\text { (cc./100 8./min.) }\end{array}$} & \multicolumn{2}{|c|}{$\begin{array}{c}\text { (CVR) } \\
\text { Cerebral } \\
\text { vascular } \\
\text { resistance } \\
(m m . H g) \\
\left(c c . / 100 \text { g. } / \text { min. }^{\prime}\right)\end{array}$} & \multicolumn{2}{|c|}{$\begin{array}{c}\text { (MABP) } \\
\begin{array}{c}\text { Mean arterial } \\
\text { blood } \\
\text { pressure }\end{array} \\
(\mathrm{mm} . \mathrm{Hg})\end{array}$} & \multicolumn{2}{|c|}{$\begin{array}{c}\text { (A-V O }) \\
\text { Arterio-ven. } \\
\text { oxygen } \\
\text { difference } \\
(V o l . \%)\end{array}$} & \multicolumn{2}{|c|}{$\begin{array}{c}\text { Cerebral } \\
\text { respiratory } \\
\text { quotient }\end{array}$} \\
\hline & I & II & I & II & I & II & I & II & I & II & I & II \\
\hline $\begin{array}{l}\text { L. S. } \\
\text { M. M. } \\
\text { J. W. } \\
\text { W. N. } \\
\text { A. A. } \\
\text { R. H. } \\
\text { B. D. }\end{array}$ & $\begin{array}{l}37 \\
37 \\
71 \\
39 \\
51 \\
\mathbf{3 1} \\
\mathbf{5 3}\end{array}$ & $\begin{array}{l}\mathbf{5 0} \\
69 \\
\mathbf{6 8} \\
\mathbf{5 4} \\
\mathbf{5 5} \\
\mathbf{3 8} \\
\mathbf{5 5}\end{array}$ & $\begin{array}{l}2.0 \\
2.0 \\
3.8 \\
1.8 \\
2.7 \\
1.9 \\
2.9\end{array}$ & $\begin{array}{l}2.3 \\
2.9 \\
2.6 \\
3.0 \\
3.4 \\
3.0 \\
3.1\end{array}$ & $\begin{array}{l}3.2 \\
2.7 \\
1.4 \\
2.2 \\
2.8 \\
4.2 \\
1.8\end{array}$ & $\begin{array}{l}1.9 \\
1.6 \\
1.4 \\
1.6 \\
2.4 \\
3.3 \\
1.7\end{array}$ & $\begin{array}{r}119 \\
100 \\
99 \\
87 \\
141 \\
131 \\
98\end{array}$ & $\begin{array}{r}95 \\
109 \\
96 \\
88 \\
132 \\
126 \\
94\end{array}$ & $\begin{array}{l}\mathbf{5 . 5} \\
5.3 \\
5.4 \\
4.7 \\
5.2 \\
6.2 \\
5.4\end{array}$ & $\begin{array}{l}4.6 \\
4.2 \\
3.8 \\
5.6 \\
6.1 \\
8.0 \\
5.7\end{array}$ & $\begin{array}{l}.93 \\
.96 \\
.86 \\
.90 \\
.94 \\
.79 \\
1.00\end{array}$ & $\begin{array}{l}.80 \\
.98 \\
.92 \\
.98 \\
.95 \\
.90 \\
.95\end{array}$ \\
\hline Mean & 45.6 & 55.6 & 2.44 & 2.90 & 2.61 & 1.99* & 111 & 106 & 5.4 & 5.4 & .91 & .93 \\
\hline
\end{tabular}

I-Preoperative study

II-Post-bilateral stellate ganglionectomy study

* Denotes significant difference $(p<.02)$ 


\section{SUMMARY}

The cerebral circulation was studied in a series of seven patients before and after bilateral stellate ganglionectomy. A significant decrease in cerebrovascular resistance was found to result from stellate ganglionectomy. This decrease in cerebrovascular resistance following operation appears to be greatest in those patients with the initially slowest cerebral blood flow and initially most marked increases in cerebrovascular resistance.

\section{REFERENCES}

1. Schmidt, C. F., The present status of knowledge concerning the intrinsic control of the cerebral circulation and the effects of functional derangements in it. Federation Proc., 1944, 3, 131.

2. Leriche, R., and Fontaine, R., De l'infiltration stellaire dans les embolies cérébrales, dans les spasmes vasculaires postopératoires de l'encéphale et chez les hémiplégiques. Rev. de chir., 1936, 74, 755.

3. Mackey, W. A., and Scott, L. D. W., The treatment of apoplexy by infiltration of the stellate ganglion with novocain. Brit. M. J., 1938, $2,1$.

4. Risteen, W. A., and Volpitto, P. P., Role of stellate ganglion block in certain neurologic disorders. South. M. J., 1946, 39, 431.

5. Gilbert, N. C., and de Takats, G., Emergency treatment of apoplexy. J.A.M.A., 1948, 136, 659.

6. Harmel, M. H., Hafkenschiel, J. H., Austin, G. M., Crumpton, C. W., and Kety, S. S., The effect of bilateral stellate ganglion block on the cerebral circulation in normotensive and hypertensive patients. J. Clin. Invest., 1949, 28, 415.

7. Kety, S. S., The quantitative determination of cerebral blood flow in man, in Methods in Medical Research, edited by Potter, V. R. Year Book Publishers, Chicago, 1948, Vol. 1.

8. Scheinberg, P., Cerebral blood flow in vascular disease of the brain, with observations on the effects of stellate ganglion block. Am. J. Med., 1950, 8, 139.

9. Peters, J. P., and Van Slyke, D. D., Quantitative Clinical Chemistry. Vol. I. Interpretations. Williams \& Wilkins, Baltimore, 1931.

10. Shenkin, H. A., Harmel, M. H., and Kety, S. S., Dynamic anatomy of the cerebral circulation. Arch. Neurol. \& Psychiat., 1948, 60, 240. 